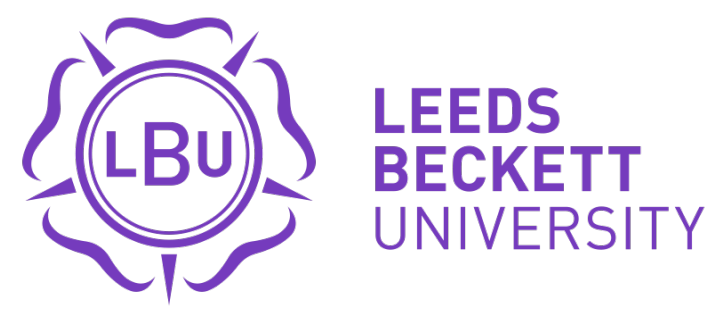

Citation:

Carroll, S and Tsakirides, $C$ and Hobkirk, J and Moxon, JWA and Moxon, JWD and Dudfield, M and Ingle, L (2011) Differential improvements in lipid profiles and Framingham recurrent risk score in patients with and without diabetes mellitus undergoing long-term cardiac rehabilitation. Arch Phys Med Rehabil, 92 (9). pp. 1382-1387. ISSN 1532-821X DOI: https://doi.org/10.1016/j.apmr.2011.04.013

Link to Leeds Beckett Repository record:

https://eprints.leedsbeckett.ac.uk/id/eprint/4611/

Document Version:

Article (Published Version)

The aim of the Leeds Beckett Repository is to provide open access to our research, as required by funder policies and permitted by publishers and copyright law.

The Leeds Beckett repository holds a wide range of publications, each of which has been checked for copyright and the relevant embargo period has been applied by the Research Services team.

We operate on a standard take-down policy. If you are the author or publisher of an output and you would like it removed from the repository, please contact us and we will investigate on a case-by-case basis.

Each thesis in the repository has been cleared where necessary by the author for third party copyright. If you would like a thesis to be removed from the repository or believe there is an issue with copyright, please contact us on openaccess@leedsbeckett.ac.uk and we will investigate on a case-by-case basis. 


\title{
Differential Improvements in Lipid Profiles and Framingham Recurrent Risk Score in Patients With and Without Diabetes Mellitus Undergoing Long-Term Cardiac Rehabilitation
}

\author{
Sean Carroll, PhD, Costas Tsakirides, MSc, James Hobkirk, BSc, James W.A. Moxon, MBChB, \\ James W.D. Moxon, MBBS, DipSportMed, Michael Dudfield, MSc, Lee Ingle, PhD
}

ABSTRACT. Carroll S, Tsakirides C, Hobkirk J, Moxon JWA, Moxon JWD, Dudfield M, Ingle L. Differential improvements in lipid profiles and Framingham recurrent risk score in patients with and without diabetes mellitus undergoing longterm cardiac rehabilitation. Arch Phys Med Rehabil 2011;92: 1382-7.

Objective: To determine whether lipid profiles and recurrent coronary heart disease (CHD) risk could be modified in patients with and without diabetes mellitus undergoing long-term cardiac rehabilitation $(\mathrm{CR})$.

Design: Retrospective analysis of patient case records.

Setting: Community-based phase $4 \mathrm{CR}$ program.

Participants: Patients without diabetes $(n=154 ; 89 \%$ men; mean $\pm \mathrm{SD}$ age, 59.6 $\pm 8.5 \mathrm{y}$; body mass index [BMI], $\left.27.0 \pm 3.5 \mathrm{~kg} / \mathrm{m}^{2}\right)$ and patients with diabetes $(\mathrm{n}=20 ; 81 \% \mathrm{men}$; mean age, $63.0 \pm 8.7 \mathrm{y} ; \mathrm{BMI}, 28.7 \pm 3.3 \mathrm{~kg} / \mathrm{m}^{2}$ ) who completed 15 months of CR.

Interventions: Exercise testing and training, risk profiling, and risk-factor education.

Main Outcome Measures: Cardiometabolic risk factors and 2to 4-year Framingham recurrent CHD risk scores were assessed.

Results: At follow up, a significant main effect for time was evident for decreased body mass and waist circumference and improved low-density lipoprotein cholesterol (LDL-C) level and submaximal cardiorespiratory fitness (all $P<.05$ ), showing the benefits of $\mathrm{CR}$ in both groups. However, a significant group-by-time interaction effect was evident for high-density lipoprotein cholesterol (HDL-C) level and total cholesterol (TC)/HDL-C ratio (both $P<.05$ ). TC/HDL-C ratio improved $(5.0 \pm 1.5$ to $4.4 \pm 1.3)$ in patients without diabetes, but showed no improvement in patients with diabetes $(4.8 \pm 1.6 \mathrm{v} 4.9 \pm 1.6)$.

Conclusions: We showed that numerous anthropometric, submaximal fitness, and cardiometabolic risk variables (especially LDL-C level) improved significantly after long-term CR. However, some aspects of cardiometabolic risk (measures incorporating $\mathrm{TC}$ and HDL-C) improved significantly in only the nondiabetic group.

Key Words: Cardiac rehabilitation; Cardiometabolic risk; Cardiorespiratory fitness; Exercise training; High-density lipoprotein cholesterol; Low-density lipoprotein cholesterol; Rehabilitation; Type 2 diabetes.
(C) 2011 by the American Congress of Rehabilitation Medicine

GEVERAL RECENT REPORTS from contemporary large international databases, such as the REeduction of Atherothrombosis for Continued Health Registry, showed that stable outpatients with coronary heart disease (CHD), especially those with concomitant diabetes, experience high rates of subsequent CHD events despite the use of various standard medications and medical treatments. ${ }^{1}$ International survey data also showed substantial residual cardiometabolic risk in patients with CHD, especially obesity, dyslipidemia, increased blood pressure, and impaired glucose tolerance. These are highly prevalent, largely undertreated, and undercontrolled. ${ }^{2-4}$

The need for intensive, longitudinal, multimodal optimal medical therapy in high-risk CHD groups ${ }^{5}$ has been reiterated recently. ${ }^{6-10}$ Several studies ${ }^{1-16}$ reporting somewhat conflicting results compared the effects of cardiac rehabilitation (CR) between patients with and without diabetes. Moreover, longterm lifestyle-induced improvements in cardiometabolic risk factors in patients with type 2 diabetes without CHD also were inconsistent. ${ }^{17,18}$ Therefore, the aim of our study was to evaluate the impact of a 15-month comprehensive outpatient CR program on cardiometabolic and Framingham recurrent risk profiles in cardiac patients with and without diabetes mellitus.

\begin{tabular}{ll} 
& List of Abbreviations \\
\hline 4 S & Scandinavian Simvastatin Survival Study \\
BMI & body mass index \\
CHD & coronary heart disease \\
CR & cardiac rehabilitation \\
CRF & cardiorespiratory fitness \\
DANSUK & DANish StUdy of impaired glucose \\
& metabolism in the settings of cardiac \\
& rehabilitation \\
ECG & electrocardiogram \\
ETT & exercise tolerance test \\
EUROASPIRE & European Action on Secondary \\
& Prevention through Intervention to \\
& Reduce Events \\
FRS & Framingham risk score \\
HDL-C & high-density lipoprotein cholesterol \\
LDL-C & low-density lipoprotein cholesterol \\
RPE & rating of perceived exertion \\
SCRIP & Stanford Coronary Risk Intervention \\
& Project \\
TC & total cholesterol
\end{tabular}

From the Leeds Metropolitan University, Leeds, United Kingdom.

No commercial party having a direct financial interest in the results of the research supporting this article has or will confer a benefit on the authors or on any organization with which the authors are associated.

Correspondence to Lee Ingle, PhD, Carnegie Research Institute, 209 Fairfax Hall, Leeds Metropolitan University, Beckett Park, Headingley, Leeds LS6 3QS, UK, e-mail:l.ingle@leedsmet.ac.uk. Reprints are not available from the author.

0003-9993/11/9209-00039\$36.00/0

doi:10.1016/j.apmr.2011.04.013 


\section{METHODS}

\section{Participants}

Consecutive referrals were extracted from the Heart Watch community-based phase $4 \mathrm{CR}$ program, Leeds, West Yorkshire, United Kingdom. The program was developed and delivered by Leeds City Council. All eligible patients had a previous clinical diagnosis of CHD and were referred by their general practitioner, consultant cardiologist, or hospital-based CR staff. Written informed consent for exercise testing and training was obtained from all patients. Ethical approval was received from the Leeds Metropolitan University Faculty Ethics Committee.

The CR program consisted of clinical evaluation, exercise testing, risk-factor education, and counseling sessions on an ongoing regular basis. All patients had been discharged from the hospital for at least 12 weeks and were clinically stable, asymptomatic, and deemed capable to self-monitor and regulate exercise training. Patients underwent a baseline clinical evaluation that included medical and cardiac history, anthropometry, blood pressure, lipoprotein-lipid profiles, an electrocardiogram (ECG) at rest, and a submaximal cardiorespiratory fitness (CRF) test that included electrocardiography. Patients were reassessed at 3 and 15 months, including physician review of symptoms and medications and adherence to exercise training. Exercise adherence was confirmed by checking weekly attendance registers of exercise classes.

CR medical staff were not responsible for ongoing therapeutic management, but routinely informed patients' general practitioners of changes in symptoms, adverse cardiometabolic risk, and exercise testing abnormalities. We retrospectively analyzed patient records to evaluate changes in these variables. Our inclusion criteria were patients who (1) had undergone 2 consecutive CRF tests and simultaneous blood tests at baseline and 15 months, (2) presented with a diagnosis of myocardial infarction or CHD or had undergone bypass surgery (coronary artery bypass grafting) or percutaneous transluminal coronary angioplasty, and (3) were nonsmokers. Patients with diabetes had a confirmed diagnosis of type 1 or 2 diabetes mellitus on baseline referral. Patients with other diseases, such as valvular heart disease, peripheral vascular disease, cardiomyopathies, or cardiac arrhythmia syndromes, or those with a pacemaker were excluded. For purposes of our study, patients were stratified into 2 groups: (1) participants without and (2) with diabetes.

\section{Procedures}

Anthropometric data, including stature, body mass, and waist circumference, were collected. Waist circumference was measured at the level of the umbilicus, and hip circumference, at the level of the greater trochanters (nearest $0.5 \mathrm{~cm}$ ) by using a flexible tape with the subject standing. Venous blood sampling was conducted between 9.30 AM and 12.30 PM after an overnight fast of at least 12 hours. Blood samples were drawn with minimal venous stasis from an antecubital vein into Monovette $^{\mathrm{a}}$ serum tubes. From January 1994 to August 1996, lipid analyses were undertaken as routine clinical samples at Seacroft Hospital Biochemistry Department, Leeds, accredited by Clinical Pathology Accreditation (UK). Serum high-density lipoprotein cholesterol (HDL-C) was measured in all normolipemic samples (fasting triglycerides $<4.0 \mathrm{mmol} / \mathrm{L}$ ) by using the heparin manganese-chloride method. The laboratory subscribed to the UK National External Quality Assurance Scheme during the study period. Lipid analyses were performed on a Hitachi 747 analyzer $^{\mathrm{b}}$ using Boehringer Mannheim ${ }^{\mathrm{b}}$ reagents at the Leeds General Infirmary. HDL-C level was determined by using the polyethylineglycol/aminophenazone method, with coefficients of variation for low and high HDL-C levels of $6.3 \%$ to $13.3 \%$. Maximum coefficients of variation for cholesterol and triglyceride levels derived from external quality assurance schemes were approximately 5\%. Total cholesterol (TC)/HDL-C ratio was calculated as an index of lipid-associated CHD risk and is supported by both its superior predictive power compared with TC, low-density lipoprotein cholesterol (LDL-C), or HDL-C levels and lower within-person variability. ${ }^{19}$

Systolic (Korotkoff phase I) and diastolic (Korotkoff phase V) blood pressures at rest were determined manually by using a mercury sphygmomanometer. ${ }^{c}$ These measurements usually were obtained from the right arm with the subject in a sitting position. The lower of 2 consecutive measurements obtained within 10 minutes was used. The Framingham Recurrent Risk Model $^{20}$ (Framingham risk score [FRS] model) was used to determine recurrent CHD risk for 2 and 4 years. The multivariate model included age, sex, TC level, HDL-C level, current smoking status, and presence of diabetes. Systolic blood pressure also was used in only women.

An ECG at rest was obtained with the subject in the standing position before the exercise tolerance test (ETT). The exercise test was conducted on a Marquette Max treadmill ${ }^{\mathrm{d}}$ using a 2-minute stage incremental protocol. ${ }^{21}$ Patients were encouraged to exercise up to $85 \%$ of age-predicted maximum heart rate $(220-$ age $)$ or a "very hard" rating of perceived exertion (RPE 17) using the Borg scale. ${ }^{22}$ However, the ETT was terminated if a patient presented with symptoms highlighted as contraindications by the American College of Sports Medicine. $^{23}$ Submaximal exercise testing was conducted in a nonhospital setting that was medically supervised. Following local cardiologist advice, the higher risk associated with maximal exercise testing in cardiac patients was not considered appropriate for a community environment. Exercise test outcome measures used in the present report were peak heart rate during the final exercise stage completed, highest RPE, and exercise test duration.

\section{Exercise Training Program}

The CR program was formally supervised by qualified exercise instructors. The exercise training program was 45 to 60 minutes (including warm-up stretching, aerobic/resistancebased circuit training, and cool-down). Patients were strongly encouraged to walk 30 minutes per day and attend exercise classes on 3 nonconsecutive days per week. The circuit training component involved six 4-minute stations, some with 8 different exercises. Aerobic exercise included floor and treadmill walking, leg cycling, arm-leg cycling, rowing ergometry, and bench-stepping. Resistance and floor-based sets comprised 8 different exercises performed for up to 30 seconds each. All patients wore a heart rate monitor ${ }^{\mathrm{e}}$ during exercise. Exercise intensity was modified for each patient according to exercise heart rate and electrocardiographic responses. Patients were expected to exercise to $40 \%$ to $85 \%$ of their submaximal heart rate reserve (peak treadmill exercise heart rate minus heart rate at rest), which was monitored by the exercise instructors.

\section{Statistical Analysis}

Continuous variables were presented as mean $\pm \mathrm{SD}$, and categorical data, as percentage. An arbitrary level of 5\% statistical significance was used throughout (2 tailed). Independent $t$ tests and chi-square analysis were used to identify differences in variables and proportions on cardioprotective therapies between the nondiabetic and diabetic groups at base- 
line. Independent-samples $t$ test was used to identify baseline differences between groups. To identify potentially significant group-by-time interactions, separate (group $\times$ time) analyses of variance with repeated measures for time were used, and when applicable, Bonferroni post hoc analysis was conducted. Additional subgroup analyses were undertaken (1) excluding all participants for whom lipid-lowering medication status changed during the follow-up period and (2) for participants not on statin therapy throughout the duration of the study. SPSS software, Version 17.0 $0^{\mathrm{f}}$ was used for statistical analyses, and significance was assumed at $P<.05$.

\section{RESULTS}

Patients without diabetes $(\mathrm{n}=154 ; 89 \%$ men; mean age, $59.6 \pm 8.5 \mathrm{y}$; body mass index [BMI], $27.0 \pm 3.5 \mathrm{~kg} / \mathrm{m}^{2}$ ) and patients with diabetes $(n=20 ; 81 \%$ men; mean age, $63.0 \pm 8.7 y$; BMI, $28.7 \pm 3.3 \mathrm{~kg} / \mathrm{m}^{2}$ ) completed 15 months of CR. All baseline diagnostic, anthropometric, metabolic, and exercise variables are listed in table 1. Patients with diabetes tended to be older and showed a more adverse anthropometric profile (higher BMI and waist circumference). However, there were no significant baseline differences between patients with and without diabetes in any variables except for 2- and 4-year FRSs (both $P=.001$ ) and a significantly higher prevalence of statin therapy at baseline in patients without diabetes (42\% vs $29 \%$ ). Self-reported exercise training compliance rates at 15 months, reported on clinical reassessment, were similar between groups (diabetic group, 3.0 \pm 1.5 compared with nondiabetic group, $2.9 \pm 0.9$ sessions/wk). Exercise test results showed that treadmill duration increased from 10.1 to 12.2 minutes in patients without diabetes and 8.8 to 10.4 minutes in patients with diabetes (both $P<.05$ ). Peak RPE and submaximal heart rate attained on the treadmill test did not differ between groups at baseline and follow-up (see table 1).

A main effect for time was evident for anthropometric variables (decreased body mass and waist circumference), LDL-C level (decreased), FRS at 4 years (decreased), TC level (decreased), and cardiorespiratory fitness (increased submaximal exercise test duration; $P<.05$ in all cases), showing the benefit of exercise training in both groups at follow-up (see table 1). A trend toward lower diastolic blood pressure at rest over time also was evident $(P=.069)$.

A group-by-time interaction effect was evident for HDL-C level and TC/HDL-C ratio $(P<.05)$. In patients without diabetes, TC/HDL-C ratios improved from baseline $(5.0 \pm 1.5)$ to 15 months $(4.4 \pm 1.3)$. In contrast, TC/HDL-C ratio showed no improvement in patients with diabetes $(4.8 \pm 1.6$ vs $4.9 \pm 1.6)$. FRS at 4 years improved in the nondiabetic $(17.1 \% \pm 3.4 \%$ vs $15.1 \% \pm 4.1 \%)$ and diabetic groups $(22.2 \% \pm 4.1 \%$ vs $21.6 \% \pm 5.0 \%$ ). A significant group effect (nondiabetic group lower than diabetic group) was evident for FRS $(P<.05)$. We adjusted our analyses to examine any influence of statin therapy. A subgroup analysis was performed on all patients with no change in statin therapy at 15 months (nondiabetic group, $n=128$; diabetic group, $n=16$ ). This included patients for whom statin therapy was unchanged and those not prescribed statins at any point. We found that the interaction effect remained (all $P<.05$ ) for HDL-C level, TC/HDL-C ratio, and FRS at 4 years. The analysis was re-run for all patients not on statin therapy at baseline and with no change in statin therapy status at follow-up (nondiabetic group, $n=71$; diabetic group, $\mathrm{n}=10$ ) (table 2). A group-by-time interaction effect was evident for HDL-C level in this subgroup of patients $(P<.05)$. In patients with CHD, HDL-C levels improved from baseline $(1.18 \pm 0.34 \mathrm{mmol} / \mathrm{L})$ to $15 \mathrm{months}(1.27 \pm 0.40 \mathrm{mmol} /$ L). HDL-C levels decreased in the diabetic group $(1.22 \pm 0.31$ vs $1.09 \pm 0.25 \mathrm{mmol} / \mathrm{L})$. However, no significant time or interaction effect in TC/HDL-C ratio or FRS at 4 years $(P$ for interaction effect $=.125$ and $P=.087$, respectively) was observed (data not shown). The proportion of participants using diabetic medication was unchanged (see table 2).

\section{DISCUSSION}

We showed that anthropometric and submaximal fitness variables and LDL-C levels improved significantly in both the nondiabetic and diabetic groups after long-term (15mo) CR incorporating structured aerobic/resistance exercise training. Most

Table 1: Anthropometric, Metabolic, and Exercise Test Variables: Baseline and 15-Month Follow-up in Patients Without and With Diabetes

\begin{tabular}{|c|c|c|c|c|c|c|c|}
\hline \multirow[b]{2}{*}{ Variable } & \multirow[b]{2}{*}{$\begin{array}{c}\text { Baseline } \\
\text { Nondiabetic }\end{array}$} & \multirow[b]{2}{*}{$\begin{array}{c}15 \text { mo } \\
\text { Nondiabetic }\end{array}$} & \multirow[b]{2}{*}{$\begin{array}{l}\text { Baseline } \\
\text { Diabetic }\end{array}$} & \multirow[b]{2}{*}{$\begin{array}{c}15 \text { mo } \\
\text { Diabetic }\end{array}$} & \multicolumn{3}{|c|}{ Repeated-Measures ANOVA $P$} \\
\hline & & & & & Time & Group & $\begin{array}{c}\text { Time } \times \text { Group } \\
\text { Interaction }\end{array}$ \\
\hline BMI $\left(\mathrm{kg} / \mathrm{m}^{2}\right)$ & $27.0 \pm 3.5$ & $26.8 \pm 3.5$ & $28.7 \pm 3.3$ & $28.3 \pm 2.9$ & .084 & .058 & .403 \\
\hline Body mass (kg) & $79.0 \pm 12.0$ & $78.8 \pm 12.3$ & $83.4 \pm 11.3$ & $81.7 \pm 10.1$ & .033 & .201 & .125 \\
\hline Waist circumference (cm) & $95.2 \pm 9.6$ & $94.4 \pm 9.5$ & $101.5 \pm 8.9 *$ & $98.6 \pm 7.3$ & .001 & .018 & .054 \\
\hline Systolic BP at rest $(\mathrm{mmHg})$ & $143.3 \pm 20.0$ & $141.3 \pm 20.8$ & $150.0 \pm 25.0$ & $145.2 \pm 17.8$ & .133 & .224 & .536 \\
\hline Diastolic BP at rest $(\mathrm{mmHg})$ & $85.6 \pm 11.2$ & $83.8 \pm 9.4$ & $86.7 \pm 11.2$ & $83.6 \pm 14.8$ & .069 & .835 & .622 \\
\hline $\mathrm{HR}$ at rest (beats/min) & $66.5 \pm 14.3$ & $65.5 \pm 12.5$ & $72.9 \pm 16.8$ & $73.3 \pm 15.7$ & .570 & .014 & .376 \\
\hline $\mathrm{TC}(\mathrm{mmol} / \mathrm{L})$ & $5.48 \pm 1.01$ & $5.14 \pm 0.89$ & $5.36 \pm 1.49$ & $5.09 \pm 1.05$ & .007 & .681 & .734 \\
\hline HDL-C (mmol/L) & $1.17 \pm 0.30$ & $1.24 \pm 0.34$ & $1.15 \pm 0.25$ & $1.09 \pm 0.22$ & .842 & .211 & .023 \\
\hline Triglycerides (mmol/L) & $1.82 \pm 1.26$ & $1.60 \pm 0.86$ & $2.11 \pm 1.01$ & $2.10 \pm 1.26$ & .312 & .092 & .377 \\
\hline LDL-C (mmol/L) & $3.54 \pm 0.93$ & $3.20 \pm 0.82$ & $3.37 \pm 1.23$ & $3.18 \pm 0.92$ & .011 & .629 & .472 \\
\hline TC/HDL-C ratio & $4.98 \pm 1.51$ & $4.40 \pm 1.28$ & $4.84 \pm 1.60$ & $4.91 \pm 1.59$ & .074 & .535 & .024 \\
\hline Exercise HR peak (beats/min) & $126.6 \pm 19.0$ & $128.9 \pm 18.5$ & $128.9 \pm 24.3$ & $129.1 \pm 22.3$ & .467 & .773 & .542 \\
\hline Exercise RPE peak & $14.7 \pm 1.9$ & $15.2 \pm 1.7$ & $15.1 \pm 1.5$ & $15.2 \pm 1.9$ & .282 & .633 & .509 \\
\hline Exercise duration (min) & $10.1 \pm 2.7$ & $12.2 \pm 2.7$ & $8.8 \pm 3.2$ & $10.4 \pm 3.5$ & $<.0001$ & .011 & .323 \\
\hline FRS, 2 y (\%) & $8.5 \pm 2.4$ & $7.9 \pm 2.2$ & $11.5 \pm 2.7^{*}$ & $11.5 \pm 2.8$ & .123 & $<.0001$ & .055 \\
\hline FRS, 4 y (\%) & $17.1 \pm 3.4$ & $15.1 \pm 4.1$ & $22.2 \pm 4.1 *$ & $21.6 \pm 5.0$ & .114 & $<.0001$ & .051 \\
\hline
\end{tabular}

NOTE. Values expressed as mean \pm SD unless noted otherwise. Patients without diabetes, $n=151 ; p a t i e n t s$ with diabetes, $n=20$. Abbreviations: ANOVA, analysis of variance; BP, blood pressure; HR, heart rate.

* Significant baseline differences between patients without and with diabetes $(P<.05)$. 
Table 2: Proportions of Patients Using Diabetic and Cardioprotective Medications and Attainment of Therapeutic Control of TC, BP, and Clinical Obesity in Accordance With Professional Society Guidelines (Joint European Society/EUROASPIRE Surveys): Baseline and 15-Month Follow-up in the CAR and CDM Groups

\begin{tabular}{|c|c|c|c|c|}
\hline \multirow[b]{2}{*}{ Variable } & \multicolumn{2}{|c|}{ Baseline } & \multicolumn{2}{|c|}{$15 \mathrm{mo}$} \\
\hline & Nondiabetic & Diabetic & Nondiabetic & Diabetic \\
\hline Diabetic medication (\%) & NA & 39 & NA & 46 \\
\hline Statins (\%) & 40 & 35 & 51 & 45 \\
\hline$\beta$-Blockers (\%) & 42 & 46 & 41 & 46 \\
\hline ACE inhibitors (\%) & 19 & 23 & 27 & 23 \\
\hline Diuretics (\%) & 16 & 31 & 16 & 31 \\
\hline $\mathrm{TC}(<4.5 \mathrm{mmol} / \mathrm{L})$ & 18 & 35 & 23 & 25 \\
\hline Systolic BP $(<140 \mathrm{mmHg})$ & 38 & 40 & 43 & 35 \\
\hline Diastolic BP $(<90 \mathrm{mmHg})$ & 56 & 45 & 70 & 70 \\
\hline BP (<130/80mmHg) & 12 & 10 & 12 & 25 \\
\hline BMI $\left(<30.0 \mathrm{~kg} / \mathrm{m}^{2}\right)$ & 80 & 75 & 80 & 70 \\
\hline
\end{tabular}

NOTE. Values expressed as \%.

Abbreviations: ACE, angiotensin-converting enzyme; BP, blood pressure; NA, not applicable.

inpatient and outpatient $\mathrm{CR}$ programs or exercise training studies typically ranged from only 6 weeks $^{24}$ to 3 months. ${ }^{14,25,26} \mathrm{We}$ found that HDL-C level improved in the nondiabetic group after comprehensive CR. We report significant increases in the proportion of patients prescribed statin therapy, which increased by approximately $10 \%$ in patients with and without diabetes. These changes in coronary risk factors were consistent with earlier reports, ${ }^{11,26}$ including a randomized controlled trial ${ }^{17}$ showing lipid improvements, except for HDL-C level in 1 study. ${ }^{11}$ An earlier short-term study showed similar nonsignificant changes in risk factors in a large cohort of patients with diabetes. ${ }^{13}$

Our findings are consistent with other multimodal intensive interventions that significantly improved cardiometabolic risk factors. Favorable intervention changes in cardiometabolic risk compared with relatively small changes in the usual-care group also were shown in the randomized Stanford Coronary Risk Intervention Project (SCRIP) 4-year study. ${ }^{27}$ However, only a small proportion of patients with diabetes were randomly assigned (10\%-13\%) in SCRIP. Lifestyle changes were more effective than metformin for decreasing the incidence of diabetes in high-risk patients with impaired glucose metabolism. ${ }^{28,29}$ In secondary prevention settings, a 12-month Danish study investigated stepwise intensive CR (DANish StUdy of impaired glucose metabolism in the settings of cardiac rehabilitation [DANSUK] $),{ }^{30}$ including an initial 6-week period of supervised exercise training, on risk-factor profile in 104 patients with type 2 diabetes or impaired glucose tolerance. Participants were randomly assigned to hospital-based rehabilitation compared with usual care. In patients with diabetes, waist circumference, TC level, and LDL-C level ( $-3 \%$ and $9.6 \%$, respectively), but not triglyceride and HDL-C levels, decreased significantly compared with the usual-care group. Of note, proportions of patients in the DANSUK usual-care and intervention groups receiving statin therapy at study end were high ( $82 \%$ and $94 \%$, respectively).

Consistent with other reports, our patients with diabetes had significantly lower exercise capacity than patients without diabetes at baseline ${ }^{13,14,24}$ and had similar relative improvements with exercise training. An increase of $1 \mathrm{~mL} \cdot \mathrm{kg}^{-1} \cdot \mathrm{min}^{-1}$ in peak oxygen uptake is equivalent to a $9 \%$ decrease in cardiovascular-related mortality in secondary prevention settings. ${ }^{31} \mathrm{Al}-$ though we did not measure maximal oxygen uptake, we found an improvement in mean submaximal oxygen uptake of 3 to $4 \mathrm{~mL} \cdot \mathrm{kg}^{-1} \cdot \mathrm{min}^{-1}$, or approximately 1 metabolic equivalent. ${ }^{23}$ Recently, Mourot et $\mathrm{al}^{24}$ reported similar short-term improvements in exercise capacity after a multidisciplinary CR program in a large cohort of patients with CHD with and without type 2 diabetes. This generally was consistent with other studies that reported improvements of $38 \%$ in patients with diabetes and $34 \%$ in patients without diabetes after 3 months of exercise training ${ }^{24}$ or $26 \%$ in patients with diabetes after 10 weeks of training. ${ }^{13}$ Verges et al $^{12}$ reported less impressive improvements in peak oxygen uptake after 2 months of aerobic training (13\% in patients with diabetes). Likewise, exercise capacity did not significantly improve in patients with type 2 diabetes in the CR group compared with usual care in DANSUK. ${ }^{30}$ It is not clear why these discrepancies exist; however, it likely is caused by a number of factors, including differences in participant baseline characteristics (age, medication use, disease severity, prevalence of comorbid conditions, volume/intensity of exercise training), training adherence, and CRF measurement methods.

Based on the FRS, we showed that risk for a recurrent cardiac event within 4 years decreased after 15 months in the nondiabetic group compared with patients with diabetes. The higher risk reported in the diabetic group was consistent with previous findings. A revised Framingham CHD risk score ${ }^{32}$ also decreased significantly in the intensive intervention group in SCRIP compared with usual care. However, in the present investigation, only approximately $20 \%$ of study participants attained the Joint European Societies treatment target for TC level $(<4.5 \mathrm{mmol} / \mathrm{L})$. In comparison, the proportion with increased cholesterol levels decreased from $94.5 \%$ in European Action on Secondary Prevention through Intervention to Reduce Events (EUROASPIRE) 1 (1995-1996) to $42.6 \%$ in EUROASPIRE III (2006-2007), largely because of the increased use of statins. Likewise, the mentioned intensive CR studies reported end-study statin therapy rates consistently in the region of $90 \%$ in CR patients or active intervention groups. ${ }^{26,27}$

Clinicians should consider more aggressive lipid lowering (statin monotherapy or combination regimens) ${ }^{33,34}$ and angiotensin-converting enzyme-inhibitor therapy in patients with CHD, especially those with diabetes, to improve cardiometabolic risk and estimated cardiovascular endpoints. However, several studies showed cardiometabolic risk profile to deteriorate significantly after short-term $\mathrm{CR}$ on long-term followup. 35,36

\section{Study Limitations}

Several important study limitations should be highlighted. First, this was a retrospective analysis of patient case records. Patients were recruited over a considerable time frame, many before the publication and widespread dissemination of the benefits of several cardioprotective therapies in secondary prevention settings and professional society guidelines. Only $13 \%$ of our sample (all without diabetes) was recruited before publication of the Scandinavian Simvastatin Survival Study (4S). ${ }^{37}$ Most participants (84\%), including most patients with diabetes, were recruited between the seminal publication dates of the $4 \mathrm{~S}$ and subsequent Heart Protection Study ${ }^{38}$ in 2002. Only 5 participants were recruited post-2002. Participants were not randomly, assigned and both selection and referral bias may be present. We were not able to provide a comparison control group of cardiac patients not undergoing exercise training intervention. Accordingly, the influence of regression to the mean for cardiometabolic and cardiorespiratory fitness variables should be considered. Most patients referred for rehabil- 
itation were men, and the findings may not be generalizable to female outpatients without diabetes. In this cohort, referred patients with diabetes constituted only a small proportion of patients and relatively few completed 15 months of CR. The first EUROASPIRE survey (1995-1996) ${ }^{39}$ also reported low representation of both women and patients with diabetes ( $20.7 \%$ and $17.4 \%$, respectively). It also is important to consider that the FRS is not without limitations. The risk algorithm was derived from the original Framingham cohort, predating many medical and surgical treatment advances for secondary prevention of CHD. Obesity and associated conditions such as diabetes were far less prevalent in the cohort of patients with preexisting cardiac disease in the original Framingham study. ${ }^{20}$ Other important risk factors in secondary prevention, such as ischemic history, other vascular comorbid conditions, ${ }^{2}$ cardioprotective medications, and contemporary risk biomarkers (such as N-terminal pro-brain natriuretic peptide or high-sensitivity C-reactive protein) were not considered. Finally, although our study showed improvements in Framingham recurrent risk estimation, it was not designed to assess subsequent cardiovascular events. Further studies of larger cohorts with longer follow-up are required to show subsequent clinical prognosis in patients with and without diabetes.

\section{CONCLUSIONS}

We showed that numerous anthropometric, submaximal fitness, and cardiometabolic risk variables (especially LDL-C level) improved significantly after long-term CR. However, some aspects of cardiometabolic risk (measures incorporating TC and HDL-C levels) improved significantly in only the nondiabetic group. Optimal medical therapy, a healthy lifestyle with regular physical exercise, and coronary interventions are interdependent treatment strategies. ${ }^{40}$ This long-term outpatient community-based CR program appeared efficacious in decreasing residual risk in $\mathrm{CHD}$ groups.

Acknowledgments: We thank Mr Steve Lawton for continued coordination of the Heart Watch program.

\section{References}

1. Bhatt DL, Eagle KA, Ohman EM, et al; REACH Registry Investigators. Comparative determinants of 4-year cardiovascular event rates in stable outpatients at risk of or with atherothrombosis. JAMA 2010;304:1350-7.

2. Bhatt DL, Steg PG, Ohman EM, et al; REACH Registry Investigators. International prevalence, recognition, and treatment of cardiovascular risk factors in outpatients with atherothrombosis. JAMA 2006;295:180-9.

3. Kotseva K, Wood D, De Backer G, De Bacquer D, Pyörälä K, Keil U; EUROASPIRE Study Group. Cardiovascular prevention guidelines in daily practice: a comparison of EUROASPIRE I, II, and III surveys in eight European countries. Lancet 2009;373:929-40.

4. Pyörälä K, Lehto S, De Bacquer D, et al; EUROASPIRE I Group; EUROASPIRE II Group. Risk factor management in diabetic and non-diabetic patients with coronary heart disease. Findings from the EUROASPIRE I AND II surveys. Diabetologia 2004;47:1257-65.

5. Dzau VJ, Antman EM, Black HR, et al. The cardiovascular disease continuum validated: clinical evidence of improved patient outcomes: part I: pathophysiology and clinical trial evidence (risk factors through stable coronary artery disease). Circulation 2006;114:2850-70.

6. Boden WE, Taggart DP. Diabetes with coronary disease-a moving target amid evolving therapies? N Engl J Med 2009;360: 2570-2.
7. O'Keefe JH, Carter MD, Lavie CJ. Primary and secondary prevention of cardiovascular diseases: a practical evidence-based approach. Mayo Clin Proc 2009;84:741-57.

8. Lavie CJ, Thomas RJ, Squires RW, Allison TG, Milani RV. Exercise training and cardiac rehabilitation in primary and secondary prevention of coronary heart disease. Mayo Clin Proc 2009;84:373-83.

9. Milani RV, Lavie CJ. Prevalence and profile of metabolic syndrome in patients following acute coronary events and effects of therapeutic lifestyle change with cardiac rehabilitation. Am J Cardiol 2003;92:50-4.

10. O'Connor CM, Whellan DJ, Lee KL, et al; HF-ACTION Investigators. Efficacy and safety of exercise training in patients with chronic heart failure: HF-ACTION randomized controlled trial. JAMA 2009;301:1439-50.

11. Pischke CR, Weidner G, Elliott-Eller M, et al. Comparison of coronary risk factors and quality of life in coronary artery disease patients with versus without diabetes mellitus. Am J Cardiol 2006;97:1267-73.

12. Verges B, Patois-Verges B, Cohen M, Lucas B, Galland-Jos C, Casillas JM. Effects of cardiac rehabilitation on exercise capacity in type 2 diabetic patients with coronary artery disease. Diabet Med 2004;21:889-95.

13. Banzer JA, Maguire TE, Kennedy CM, O’Malley CJ, Balady GJ. Results of cardiac rehabilitation in patients with diabetes mellitus. Am J Cardiol 2004;93:81-4.

14. Hindman L, Falko JM, LaLonde M, Snow R, Caulin-Glaser T. Clinical profile and outcomes of diabetic and nondiabetic patients in cardiac rehabilitation. Am Heart J 2005;150:1046-51.

15. Lavie CJ, Milani RV. Cardiac rehabilitation and exercise training programs in metabolic syndrome and diabetes. J Cardiopulm Rehabil 2005;25:59-66.

16. Svacinova H, Novakova M, Placheta Z, et al. Benefit of combined cardiac rehabilitation on exercise capacity and cardiovascular parameters in patients with type 2 diabetes. Tohoku J Exp Med 2008;215:103-11.

17. Sigal RJ, Kenny GP, Boulé NG, et al. Effects of aerobic training, resistance training, or both on glycemic control in type 2 diabetes: a randomized trial. Ann Intern Med 2007;147:357-69.

18. Look AHEAD Research Group, Wing RR. Long-term effects of a lifestyle intervention on weight and cardiovascular risk factors in individuals with type 2 diabetes mellitus: four-year results of the Look AHEAD trial. Arch Intern Med 2010;170:1566-75.

19. Thompson G. Which lipid fraction is the target and how often should this be monitored? Heart 2010;96:413-4.

20. D'Agostino RB, Russell MW, Huse DM, et al. Primary and subsequent coronary risk appraisal: new results from the Framingham Study. Am Heart J 2000;139:272-81.

21. Lehmann G, Schmid S, Ammer R, Schomig A, Alt E. Evaluation of a new treadmill exercise protocol. Chest 1997;112:98-106.

22. Borg G, Hassmen P, Lagerstrom M. Perceived exertion related to heart rate and blood lactate during arm and leg exercise. Eur J Appl Physiol Occup Physiol 1987;56:679-85.

23. American College of Sports Medicine. Guidelines for exercise testing and prescription. 8th ed. London: Williams \& Wilkins; 2010.

24. Mourot L, Boussuges A, Maunier S, et al. Cardiovascular rehabilitation in patients with diabetes. J Cardiopulm Rehabil Prev 2010;30:157-64.

25. Milani RV, Lavie CJ. Behavioral differences and effects of cardiac rehabilitation in diabetic patients following cardiac events. Am J Med 1996;100:517-23.

26. Völler H, Reibis R, Pittrow D, et al. Secondary prevention of diabetic patients with coronary artery disease in cardiac rehabilitation: risk factors, treatment and target level attainment. Curr Med Res Opin 2009;25:879-90. 
27. Haskell WL, Alderman EL, Fair JM, et al. Effects of intensive multiple risk factor reduction on coronary atherosclerosis and clinical cardiac events in men and women with coronary artery disease. The Stanford Coronary Risk Intervention Project (SCRIP). Circulation 1994;89:975-90.

28. Knowler WC, Barrett-Connor E, Fowler SE, et al; Diabetes Prevention Program Research Group. Reduction in the incidence of type 2 diabetes with lifestyle intervention or metformin. N Engl J Med 2002;346:393-403.

29. Tuomilehto J, Lindström J, Eriksson JG, et al; Finnish Diabetes Prevention Study Group. Prevention of type 2 diabetes mellitus by changes in lifestyle among subjects with impaired glucose tolerance. N Engl J Med 2001;344:1343-50.

30. Soja AM, Zwisler AD, Frederiksen M, et al. Use of intensified comprehensive cardiac rehabilitation to improve risk factor control in patients with type 2 diabetes mellitus or impaired glucose tolerance - the randomized DANish StUdy of impaired glucose metabolism in the settings of cardiac rehabilitation (DANSUK) study. Am Heart J 2007;153:621-8.

31. Kavanagh T, Mertens DJ, Hamm LF, et al. Prediction of long-term prognosis in 12169 men referred for cardiac rehabilitation. Circulation 2002;106:666-71.

32. Anderson KM, Odell PM, Wilson PW, Kannel WB. Cardiovascular disease risk profiles. Am Heart J 1991;121(1 Pt 2):293-8.

33. Rotella CM, Zaninelli A, Le Grazie C, Hanson ME, Gensini GF. Ezetimibe/simvastatin vs simvastatin in coronary heart disease patients with or without diabetes. Lipids Health Dis 2010;9:80.

34. Bardini G, Giorda CB, Pontiroli AE, Le Grazie C, Rotella CM. Ezetimibe + simvastatin versus doubling the dose of simvastatin in high cardiovascular risk diabetics: a multicenter, randomized trial (the LEAD Study). Cardiovasc Diabetol 2010;9:20.

35. Hansen D, Dendale P, Raskin A, et al. Long-term effect of rehabilitation in coronary artery disease patients: randomized clin- ical trial of the impact of exercise volume. Clin Rehabil 2010;24:319-27.

36. Giallauria F, Lucci R, D'Agostino M, et al. Two-year multicomprehensive secondary prevention program: favorable effects on cardiovascular functional capacity and coronary risk profile after acute myocardial infarction. J Cardiovasc Med (Hagerstown) 2009; 10:772-80

37. [No authors listed]. Randomised trial of cholesterol lowering in 4444 patients with coronary heart disease: the Scandinavian Simvastatin Survival Study (4S). Lancet 1994;19;344:1383-9.

38. Heart Protection Study Collaborative Group. MRC/BHF Heart Protection Study of cholesterol lowering with simvastatin in 20,536 high-risk individuals: a randomised placebo-controlled trial. Lancet 2002;360:7-22.

39. EUROASPIRE. A European Society of Cardiology survey of secondary prevention of coronary heart disease: principal results. EUROASPIRE Study Group. European Action on Secondary Prevention through Intervention to Reduce Events. Eur Heart J 1997; 18:1569-82.

40. Gielen S, Sandri M, Schuler G, Teupser D. Risk factor management: antiatherogenic therapies. Eur J Cardiovasc Prev Rehabil 2009;16(Suppl 2):S29-36.

\section{Suppliers}

a. Sarstedt AG \& Co, Sarstedtstraße, Postfach 1220, 51582 Nümbrecht, Germany.

b. Roche Diagnostics, 9115 Hague Rd, PO Box 50457, Indianapolis, IN 46250-0457.

c. Accoson Works, Vale Rd, London, N4 1PS, UK.

d. General Electric Company (W2E). 3135 Easton Turnpike, Fairfield, CT 06828.

e. Professorintie 5, FIN-90440 Kempele, Finland.

f. SPSS Inc, $233 \mathrm{~S}$ Wacker Dr, 11th Fl, Chicago, IL 60606. 